\title{
On the Simultaneity of Innovations and Market Structure
}

\author{
By W. Pohlmeier ${ }^{1}$
}

\begin{abstract}
This paper examines the determinants of innovations and market structure within a simultaneous framework. From a competitive fringe model, quasi-conditional factor demand functions are derived that explain product and process innovations in terms of factor prices and market structure variables such as relative firm size, market size, and the concentration ratio where the latter set of variables result from the same optimizing process.

Empirical evidence is gained from a cross section of 2276 West German firms in the manufacturing sector. In contrast to many other empirical studies, product and process innovations are measured by two dichotomous variables. An exogeneity test for the probit model is worked out and the conditional maximum likelihood estimator that emerges from this test is applied. The results show that simultaneity does matter, even if innovations are explained by market structure variables at the firm level. Accounting for endogeneity and cross-equation restrictions changes the results substantially.
\end{abstract}

\section{Introduction}

Innovative activity, either provided by new product developments or improvements in the technical equipment of firms, are considered to be major sources of structural change, growth, and international competitiveness. In the rapidly evolving literature on innovation and invention, numerous empirical studies have tried to test the four most popular hypotheses on the determinants of innovation. ${ }^{2}$ According to Schumpeter's earlier works [e.g. Schumpeter (1934)], expectations of a temporary monopoly and the ability to enjoy large profits while the monopoly lasts cause an entrepreneur to introduce innovations. This

\footnotetext{
1 Winfried Pohlmeier, Fakultät für Volkswirtschaftslehre und Statistik, Seminargebäude A5, 6800 Mannheim 1.

This paper is part of my dissertation (Pohlmeier 1989). I would like to thank Zvi Griliches, Heinz König, Francois Laisney and two anonymous referees for their valuable comments. Financial support by the Deutsche Forschungsgemeinschaft is gratefully acknowledged.

2 Surveys about the state of the art are given by Scherer (1980, 1984), Kamien and Schwartz (1982) and Griliches (1984); for a recent survey on empirical innovations studies see Coombs, Saviotti, Walsh (1987), Chapter 5.
} 
hypothesis, sometimes called Schumpeter Mark I, was modified in later works [Schumpeter (1942)] where Schumpeter put the emphasis on the importance of existing monopolies as pace-makers for innovative activity (Schumpeter Mark II). A third hypothesis sheds more light on the role of firm size. According to Galbraith (1952), large firm size is essential to the success of productive changes. Larger firms can provide economies of scale in production and innovation, which guarantee sufficient resources necessary for the successful competition of intended improvements. Finally, Schmookler (1966) stressed the importance of growth in demand for products as being a determinant of innovative activity.

However, only a few studies emphasize the reverse causation from innovations (or R\&D) to market structure which finds its theoretical basis in Schumpeter's notion of "creative destruction", where market structure is influenced by past and current innovative success and failures. More precisely, the innovation process generates transient market power which is in turn eroded by rival innovation and imitation.

Numerous theoretical papers have attempted to take into account the simultaneity issue within a more or less neoclassical framework [e.g. Dasgupta and Stiglitz (1980a,b), Futia (1980), Lee and Wilde (1980), Levin and Reiss (1984)]. Dasgupta and Stiglitz (1980a) argue that except in the short run, market structure and innovation are determined simultaneously. Unlike the neoSchumpeterian thesis, they claim that the relationship between innovation and market structure should not be regarded as a causal one. However, most of the empirical literature on the determinants of innovation and market structure somewhat neglected their findings.

This paper tries to reduce the gap between the existing theoretical literature and the empirical studies on innovation. The determinants of innovative activity are estimated using relevant firm level data that have been included in the Ifo Institute (Munich) business survey test since 1979. Contrary to many other studies which use intermediate output variables such as $R \& D$ expenditures as a measure of innovative performance, the econometric models presented in this paper use output variables and treat product and process innovative activity as continuous latent variables with two dichotomous variables as observable counterparts. Unlike many previous studies, we account for the potential endogeneity of market structure variables in the sense of Dasgupta and Stiglitz. Moreover, since both product and process innovative activity are due to the same optimizing process, restrictions on the parameters across the structural equations are included in the estimation as a first step towards a structural econometric modelling of innovative activity at the firm level.

In Section 2 a simple competitive fringe model is developed, explaining the firm's optimal levels of product and process innovative activity in terms of market structure variables such as relative firm size, the total market size and the concentration ratio, where these market structure variables result from the same optimizing process. Section 3 presents the data. In Section 4 the probit version of the Smith-Blundell test for exogeneity is worked out in a way that is suitable to test for the potential exogeneity of the market structure variables. With the condi- 
tional maximum likelihood estimator that emerges from this test, it is possible to estimate limited dependent variable models with endogenous explanatory variables. Section 5 presents the econometric evidence of various empirical specifications based on conditional maximum likelihood probit and bivariate maximum likelihood probit estimation techniques. Section 6 presents concluding remarks.

\section{The Model}

In this section a straightforward modification of a competitive fringe model that has frequently been used in the literature on structure performance will be worked out in order to serve as an organizing device for the econometric specification. The market structure assumed is characterized by a number of monopolistic competitors and a competitive fringe where the two groups of firms reveal different price setting behavior. Output is produced by the two input factors, labor and process innovations, according to a neoclassical production function. Besides the two factor inputs, the firm has to choose the optimal level of product innovations. Product and process innovations are not costless and can be purchased like labor, at constant unit costs. In this model a change in the level of product innovative activity is interpreted as a change in product quality, i.e. product innovative activity is regarded as an improvement of the product in consumer's eyes by satisfying latent demands more effectively. For the dominant firm under consideration, the main difference between product and process innovations is that a change in product innovations affects the firm's output price directly, while a change in process innovations affects production possibilities. Via a change in output, the latter implies a different market price due to the monopolistic market structure.

Total market demand, $Q$, will be served by the outputs of the $n$ dominant firms which face a downward sloping total market demand curve and the output of the competitive fringe, $x$. Firm $i$ is able to charge a higher price by increasing its level of product innovations. Thus the firm's profit maximization problem is defined by:

$$
\begin{aligned}
& \max _{N_{i}, T_{i}, I_{i}} \Pi_{i}=p_{i}\left(I_{i}, Q\right) \cdot q_{i}\left(N_{i}, T_{i}\right)-w_{i} N_{i}-v_{i} T_{i}-r_{i} I_{i} \\
& \text { subject to: } Q=\sum_{j=1}^{n} q_{j}+x
\end{aligned}
$$

where $p_{i}(\cdot)$

number of employees, $T_{i}$, the level of process innovations, and $I_{i}$ 
product innovations. $w_{i}$, parameters.

In order to obtain a tractable theoretical model that can be used as a guide-line for the parametric specification of the econometric model, a few more assumptions have to be made: i) the production function is of Cobb-Douglas form with constant returns to scale: $q_{i}$

isoelastic:

$$
p_{i}=p_{0} I_{i}^{\gamma} Q^{-1 / \varepsilon} \quad 0<\gamma<1 ; \varepsilon>0
$$

where $\varepsilon$ is the price elasticity of total market demand. Moreover, we assume that the supply function of the competitive fringe is also isoelastic. The first-order conditions yield the well-known equality of marginal revenue products and corresponding factor prices:

$$
\begin{aligned}
& p_{i}\left(1-m_{i}\right) \alpha \frac{q_{i}}{N_{i}}-w_{i}=0 \\
& p_{i}\left(1-m_{i}\right)(1-\alpha) \frac{q_{i}}{T_{i}}-v_{i}=0 \\
& p_{i} \begin{array}{l}
q_{i} \\
I_{i}
\end{array}
\end{aligned}
$$

where $-m_{i}$

output. Redefining the maximization problem in terms of cost function reveals that $m_{i}$

homogeneous of degree one, $m_{i}$

behavior, $m_{i}$

$$
m_{i}=\begin{aligned}
& q_{i} \\
& Q
\end{aligned}
$$

where

$$
\eta=\frac{\partial x}{\partial p_{i}} \underline{p}_{i} \quad K=\frac{Q-x}{Q}
$$

$\eta$ is the supply elasticity of the competitive fringe and $K$ is the $n$-firm concentration ratio of the industry. Equation (2.6) states that under Cournot behavior the 
degree of monopoly power in the terms of the Lerner index increases, ceteris paribus, with the relative firm size, $q_{i} / Q$, and the concentration ratio and is lower with a higher elasticity of total demand and a higher supply elasticity of the competitive fringe. ${ }^{3}$

It is possible to incorporate other behavioral assumptions than Cournot behavior in the model. This can be done by expressing the elasticities of conjectural variations of the monopolistic competitors in terms of observable variables such as relative firm size and institutional parameters [e.g. Neumann et al. (1985)]. However, this approach would be more or less ad hoc since one has to make assumptions on the link between endogenous variables.

Equations (2.3) - (2.5) implicitly define the firm's optimal choice of employment and innovation levels in terms of the exogenous variables and the two “semi"-exogenous variables $K$ and $Q$. The concentration ratio and the total industry output can be regarded as partly exogenous since they might vary with the actions of the other firms in the market. Assuming sufficient second-order conditions for the maximization problem hold, simple comparative statics yields the following partial derivatives [see Pohlmeier (1989), p. 173 for the derivation of these conditions]:

$$
\begin{gathered}
N=N(w, v, r, Q, K, \varepsilon, \eta) \\
-+-?-?+ \\
T=T(w, v, r, Q, K, \varepsilon, \eta) \\
+--?-?+ \\
\\
I=I(w, v, r, Q, K, \varepsilon, \eta) \\
---?-?+
\end{gathered}
$$

A few interesting results emerge from this simple model. Market concentration has a negative impact on employment and innovation. The theoretical reasoning behind this result is that an increase in $K$ raises monopoly power, which leads to a reduction of output and factor inputs. Note that employment and process innovation are substitutes, while employment and product innovations are complements. Thus, a wage increase forces a firm to invest more in process innovations and less in product innovative activities. Although there is no closed-form solution to Eqs. (2.3) - (2.5), it is possible to express the optimal levels of innovative activity in terms of the exogenous variables and the output variables relative to firm size, total market output and the concentration ratio. Assuming that unit costs of innovation are the same across firms and industries, simple algebraic transformations give the following "quasi-conditional" factor demand

\footnotetext{
$3 \quad$ Note that $\eta$ and $\varepsilon$ do not vary across industries. This assumption can be relaxed without changing the theoretical results and was made only in order to obtain a simple econometric specification.
} 
functions for process and product innovations [see Pohlmeier (1989), p. 174 for the derivation]:

$$
\begin{aligned}
& \ln T_{i}=c_{T}-\frac{1-\gamma}{\gamma} \ln \left(1-m_{i}\right)+\frac{1}{\gamma \varepsilon} \ln Q+\frac{\alpha}{\gamma} \ln w_{i} \\
& \ln I_{i}=c_{I}-\frac{1}{\gamma} \ln \left(1-m_{i}\right)+\frac{1}{\gamma \varepsilon} \ln Q+\frac{\alpha}{\gamma} \ln w_{i} .
\end{aligned}
$$

Equations (2.10) and (2.11) might be called conditional demand functions because they express optimal factor inputs in terms of factor prices and output variables. The prefix "quasi" is used to indicate that the factor demands do not result from cost minimization. Substituting (2.6) into the specifications (2.10) and (2.11) produces a positive relationship between the two modes of innovation and the concentration ratio. Keeping in mind the results obtained from the comparative statics, it is clear that empirical findings showing a significant positive relationship between innovations and market concentration according to Schumpeter's Mark II hypothesis do not necessarily reflect a positive causal relationship. Like the two equations above, equations relating measures of innovative activity to the concentration ratio simply reflect transformations of first-order conditions. In terms of the simple model presented here, an observed positive relationship between innovation and market concentration given relative firm size and total industry output is consistent with a negative causal relationship as indicated by Eqs. (2.8) and (2.9).

Since the term $\ln \left(1-m_{i}\right)$ is a highly nonlinear function of its arguments, the following simplifying specification for the econometric model will be used:

$$
\ln \left(1-m_{i}\right) \approx-m_{i}=-a_{0}-a_{1} D D_{i}^{*}-a_{2} D F_{i}^{*}-a_{3} \ln S_{i}-a_{4} \ln K
$$

where $S_{i}$ is a measure of the relative firm size. $D D_{i}^{*}$ and $D F_{i}^{*}$ reflect demand expectations for the domestic and the foreign markets. These two variables are included in the econometric specification in order to account for the firm's individual assessment of its market prospects in the sense of Schmookler. If the theory is correct, all parameters appearing in Eq. (2.12) should be positive. Although the model is purely neoclassical, many of the explanatory variables that the neo-Schumpeterian literature regards as important determinants in explaining innovations appear in Eqs. (2.9) and (2.10). Moreover, as was pointed out by Dasgupta and Stiglitz (1980a, p. 277), the size of the market does influence the level of the firm's innovative activities. 


\section{The Data}

Empirical results are based on a cross section of 2276 West German firms collected by the Ifo Institute in 1984. This data set contains special additional questions concerning the innovative activity of firms in the manufacturing sector. These questions are included once a year in the monthly business survey. Firms are classified by main product groups and can be related to the standard industrial group classification of the German statistical office. This allows merging data at the 2-digit industry level of the statistical office with the survey data.

From the Ifo survey, the following variables at firm level are used:

$N: \quad$ number of employees

I: $\quad$ product innovations realized (1: yes; $0:$ no)

T: $\quad$ process innovations realized (1: yes; $0:$ no)

$D D^{*}$ : expected long-run change of internal demand for the respective market (1: positive; 0 : otherwise. The time horizon is approximately five years.)

$D F^{*}$ : expected long-run change of external demand for the respective market (measured the same way as $D D^{*}$ ).

We merge the following data at the 2-digit industry level using the German Statistical Yearbook (1986):
W: average labour costs per employee, including employers' social security contributions, 1984
$K$ : concentration ratio, share of the three largest firms of the total sales of the sector, 1983
$Q: \quad$ market size, turnover of the industry in billions (German Marks), 1984
$S: \quad$ relative firm size, constructed as the firm's number of employees $(N)$ as a share of total employment in the corresponding industry.

Most of the existing literature relating innovative activity to firm size of market concentration uses $R \& D$ expenditures as a measure of innovative performance. Link (1980) argues that this procedure is not qualitatively equivalent to measuring innovative output because the transformation between R\&D inputs and innovative success is not necessarily monotonic. This is supported by theoretical findings of Kamien and Schwartz (1969) and empirical evidence [Link (1978)]. Our data allows us to take this point into account; $I$ and $T$ yield direct measures of innovative output. Finally, using R\&D expenditures as an indicator of the firm's innovative activity might be a sufficient proxy for the firm's product innovative activity but a bad one for process innovations and vice versa, depending on the industry the firm is operating in.

Using the three-firm concentration ratio for every industry can only be regarded as an approximation to the true $n$-firm concentration ratio which should also be calculated on the basis of the number of monopolistic competitors in the cor- 
responding industry. However, due to the lack of information about the true $n$ and the lack of data, we are restricted to using the three-firm concentration ratio published in the German statistical yearbook. Some major description statistics of the data are listed in Appendix A I.

\section{Testing for Exogeneity and Conditional ML-Estimation}

Due to the theoretical reasoning presented above, it is necessary to tesî whether relative firm size and the concentration ratio can be treated as weakly exogenous explanatory variables in the two quasi-conditional demand functions for product and process innovation. Although the concentration ratio is defined at the industry level, there is some evidence that approaches using this variable as an explanatory variable in cross-section models at the firm level suffer from a simultaneous equation bias [see Entorf and Pohlmeier (1990)]. Smith and Blundell (1986) develop a test for weak exogeneity in limited information simultaneous limited dependent variable models. This test can also be used simply as a test for the absence of a simultaneous equation bias. In this paper the Smith-Blundell test that has originally been derived for the censoring problem is applied within the conventional probit framework with endogenous explanatory variables. Since the Smith-Blundell test is easily adapted for the probit model with potentially endogenous explanatory variables, the underlying ideas of the test are only briefly sketched below. Let there be a simultaneous equation system of the form:

$$
\begin{aligned}
& y_{1 i}^{*}=y_{2 i}^{\prime} \gamma_{1}+x_{1 i}^{\prime} \beta_{1}+u_{1 i} \\
& y_{2 i}^{\prime}=x_{i}^{\prime} \Pi_{2}+v_{2 i}^{\prime}
\end{aligned} \quad(i=1, \ldots, N)
$$

with

$$
\left[\begin{array}{l}
u_{1 i} \\
v_{2 i}
\end{array}\right] \sim N I\left[0,\left(\begin{array}{cc}
\sigma_{1}^{2} & \sigma_{12} \\
\sigma_{21} & \sum_{22}
\end{array}\right)\right],
$$

where $y_{1 i}^{*}$ is a stochastic continuous latent variable. For $y_{1 i}^{*}$ we can observe a dichotomous variable $d_{i}$ that changes its value when $y_{1 i}^{*}$ crosses a given threshold according to the conventional specification of the probit model. $y_{2 i}$ is a $G$-vector of observable continuous endogenous variables. $x_{i}^{\prime}=\left(x_{1 i}^{\prime}, x_{2 i}^{\prime}\right)$ is a vector of observations on $k\left(=k_{1}+k_{2}\right)$ maintained weakly exogenous variables. Since $u_{1 i}$ and $v_{2 i}$ are jointly normal distributed, $u_{1 i}$ can be reparametrized conditional on $v_{2 i}$ : 


$$
u_{1 i}=v_{2 i}^{i} \alpha+\varepsilon_{i}
$$

with

$$
\begin{aligned}
& \varepsilon_{i} \sim N\left(0, \sigma_{1}^{2}-\sigma_{12} \sum_{22}^{-1} \sigma_{21}\right) \\
& \sigma_{1}^{2}-\sigma_{12} \sum_{22}^{-1} \sigma_{21} \equiv 1, \quad \alpha=\sum_{22}^{-1} \sigma_{21} .
\end{aligned}
$$

In order to achieve identification, it is necessary to restrict the variance of $\varepsilon_{i}$ to unity. This restriction corresponds to the restriction suggested by Amemiya (1978) for the maximum likelihood estimation of the simultaneous Probit model. In fact, this identification restriction is only necessary when the testing procedure is used as a conditional maximum likelihood approach to (4.1). Due to the different restrictions chosen, conditional maximum likelihood estimates and estimates obtained from Amemiya's generalized simultaneous probit estimator are not comparable. However, the Smith-Blundell test of exogeneity is also valid without restricting the variance of $\varepsilon_{i}$ to unity. Substitution of (4.3) into (4.1) yields:

$$
\begin{aligned}
y_{1 i}^{*} & =y_{2 i}^{\prime} \gamma_{1}+x_{1 i}^{\prime} \beta_{1}+v_{2 i}^{\prime} \alpha+\varepsilon_{i} \\
& =w_{i}^{\prime} \Theta+\varepsilon_{i}
\end{aligned} \quad(i=1, \ldots, N)
$$

where:

$$
w_{i}^{\prime}=\left(y_{2 i}^{\prime}, x_{1 i}^{\prime}, v_{2 i}^{\prime}\right) \quad \Theta^{\prime}=\left(\gamma_{1}^{\prime}, \beta_{1}^{\prime}, \alpha_{1}^{\prime}\right) .
$$

The concept of weak exogeneity developed by Engle, Hendry and Richard (1983) can be explained on the basis of the joint density function of the endogenous variables $g\left(y_{1 i}^{*}, y_{2 i} \mid \Omega_{i}, \lambda\right)$, where $\Omega_{i}$ represents the set of variables assumed to be weakly exogenous. The parameter vector $\lambda$ includes the parameters of the joint density. If the joint density can be decomposed in the conditional density $g_{12}\left(v_{i i}^{*} \mid y_{2 i}, \Omega_{i}, \lambda_{1}\right)$ and the marginal density $g_{2}\left(y_{2 i} \mid \Omega_{i}, \lambda_{2}\right)$ such that there are no common restrictions on $\lambda_{1}$ and $\lambda_{2}$, then $y_{2 i}$ is defined to be weakly exogenous with respect to the estimation of $\lambda_{1}$ which is in the probit model above: $\lambda_{1}=\left(\gamma_{1}^{\prime}, \beta_{1}^{\prime}\right)^{\prime}$. In this case $\lambda_{1}$ can be efficiently estimated without using information on $g_{2}$. In the probit model with endogenous explanatory variables, the test of weak exogeneity reduces to a test of the null hypothesis $\alpha=0$ since $\alpha$ reflects the common restrictions between $g_{1}$ and $g_{12}$. Since the $v_{2 i}$ 's are unknown, they have to be replaced by $\hat{v}_{2 i}$, the least squares residuals based on consistent 
estimates of $\mathrm{II}_{2}$. Hence the final regression equation to be estimated with Probit maximum likelihood method is:

$$
\begin{aligned}
y_{1 i}^{*} & =y_{2 i}^{\prime} y_{1}+x_{1 i}^{\prime} \beta_{1}+\hat{v}_{2 i}^{\prime} \alpha+e_{i} \\
& =\hat{w}_{i}^{\prime} \Theta+e_{i} \\
d_{i} & = \begin{cases}1 & \text { if } \quad e_{i}>-\hat{w}_{i}^{\prime} \Theta \\
0 & \text { otherwise }\end{cases}
\end{aligned}
$$

Using a well-known result of Amemiya (1979, Eq. 3.27), it follows for the asymptotic distribution of $\hat{\Theta}$ :

$$
\hat{\Theta}-\Theta \stackrel{a}{=}-\left\{E \frac{\partial^{2} \ln L}{\partial \Theta \partial \Theta}\right\}^{-1}\left\{\frac{\partial \ln L}{\partial \Theta}+E \frac{\partial^{2} \ln L}{\partial \Theta \partial \pi_{2}^{\prime}}\left(\hat{\pi}_{2}-\pi_{2}\right)\right\}
$$

where:

$$
\begin{aligned}
& -E\left\{\frac{\partial^{2} \ln L}{\partial \Theta \partial \Theta^{\prime}}\right\}=W^{\prime} \\
& D_{1}=\operatorname{diag}\left[\frac{\varphi\left(w_{i}^{\prime} \Theta\right)^{2}}{\Phi\left(w_{i}^{\prime} \Theta\right)\left[1-\Phi\left(w_{i}^{\prime} \Theta\right)\right]}\right] \\
& W^{\prime}=\left[w_{1}, w_{2}, \ldots, w_{N}\right\rfloor \quad \pi_{2}=\operatorname{vec} \Pi_{2} \\
& E \frac{\partial^{2} \ln L}{\partial \Theta \partial \pi_{2}^{\prime}}=\alpha^{\prime} \otimes W^{\prime} D_{1} X
\end{aligned}
$$

where $\stackrel{a}{=}$ means that both sides of the equation multiplied by $V N$ have the same asymptotic distribution. Following the proofs presented by Smith and Blundell and introducing the appropriate algebraic changes with respect to the probit model, we obtain:

$$
\hat{\Theta}-\Theta \stackrel{\mathfrak{2}}{\sim}[0, V(\hat{\Theta})],
$$


where:

$$
\begin{aligned}
V(\hat{\Theta})= & \left(W^{\prime} D_{1} W\right)^{-1}+\alpha^{\prime} \sum_{22} \alpha\left(W^{\prime} D_{1} W\right)^{-1} \\
& \times W^{\prime} D_{1} X\left(X^{\prime} X\right)^{-1} X^{\prime} D_{1} W\left(W^{\prime} D_{1} W\right)^{-1}
\end{aligned}
$$

Under the weak exogeneity hypothesis $H_{0}, V(\hat{\Theta})$ is identical to the inverse of the first term below (4.6), which is the usual covariance matrix of the probit maximum likelihood estimator. Due to the definition of $\alpha$, the $t$-values for the probit parameter estimates of $\alpha$ in (4.5 a) are the test statistics of the exogeneity test. $\Theta$ evaluated under the alternative hypothesis is a conditional maximum likelihood estimator which offers an alternative to the marginal maximum likelihood approaches for the estimation of simultaneous probit and tobit models [Amemiya (1978, 1979), Heckman (1978), Nelson and Olsen (1978) and Newey (1987)]. Since the cml-estimator is based on the score vector of the joint likelihood using $\hat{v}_{2 i}$ instead of $v_{2 i}$ it can also be interpreted as a two step generalized method of moments estimator. ${ }^{4}$ The conditional ml-estimator need not be as efficient as the maximum likelihood estimator, since the least squares estimator in the first stage does not account for possible restrictions imposed by the structure. However, with a one-step ml-estimation, efficient estimates of the structural parameters can be obtained. ${ }^{5}$ Moreover, the score test for $y_{2}$ being weakly exogenous is defined as:

$$
\frac{\partial \ln \tilde{L}_{12}}{\partial \alpha^{\prime}} S_{\alpha}^{\prime}\left(\tilde{W}^{\prime} \tilde{D}_{1} \tilde{W}\right)^{-1} S_{\alpha} \frac{\partial \ln \tilde{L}_{12}}{\partial \alpha}
$$

where:

$$
\frac{\partial \ln L_{12}}{\partial \alpha}=\sum\left[\frac{\varphi_{i}}{\Phi_{i}\left(1-\Phi_{i}\right)}\left(d_{i}-\Phi_{i}\right)\right] v_{2 i}
$$

and " $\sim$ " denotes evaluation at $H_{0} . S_{\alpha}^{\prime}$ selects out $\alpha$ from $\Theta$. We obtain an estimate of the score at $H_{0}$ by substituting $\hat{v}_{2 i}$ for $v_{2 i}$ using $\hat{\Pi}_{2}$ and using probit estimation of (4.1) (and assuming $\alpha=0$ ) to evaluate $\varphi_{i}$ and $\Phi_{i}$. The score vector of the conditional $\log$-likelihood function $\ln L_{12}$ has an interesting interpretion. Since the term in the squared brackets is the generalized error in the sense of Gourieroux et al. (1987) for the probit model, the LM test of exogeneity is to compare the sample covariance between generalized errors and reduced form error

\footnotetext{
4 This was pointed out to me by Gary Chamberlain.

5 See Pohlmeier (1989) for a comparison of cml-probit and one-step ml-estimation on the basis of a Monte-Carlo experiment.
} 
terms of the potentially endogenous variables with the corresponding estimated hypothetical covariances. The LM statistics also reveals the nature of the test as a test for the absence of a simultaneous equation bias since it checks whether the explanatory variables $\hat{v}_{2 i}$ in the extended probit equation are correlated with the generalized residuals.

Since the exogeneity test and the cml-probit estimation can be carried out only when the parameters of the structural equation to be estimated can be identified, additional explanatory variables are introduced. There are three variables at the firm level, one indicating the firm's percentage share of products being in the innovation or expansion phase of the product cycle as well as two dummy variables for the consumer and the investment goods industries. At the industry level the export ratio and the number of firms in the industry are used as additional explanatory variables.

\section{Results}

Since the econometric specification [Eqs. (2.10) - (2.12)] is linear in the variabies and the dependent variables are only observable as dichotomous indicators, the quasi-conditional factor demands for product and process innovations are estimated by simple probit first. These estimates can be compared with the cml-probit estimates, which are also given in Table 1. In order to have some measure of the goodness of fit for the probit estimates, a Pseudo $R^{2}$, proposed by Aidrich and Nelson (1984) is used. This is defined as $c /(T+c)$, where $c$ denotes the likelihood ratio statistic for the joint hypothesis that all coefficients except the intercept are zero. $T$ is the number of observations. The Pseudo $R^{2}$ can also be worked out in the bivariate probit case, where $c$ is the likelihood ratio statistic of a test against a model with zero restrictions on the slope coefficients and the correlation coefficient of the error terms, $Q$. However, Pseudo $R^{2}$-measures are not universally accepted and employed as measures of the goodness of fit. Another intuitively appealing measures of the goodness of fit that can be evaluated for a variety of models such as the linear regression model, the tobit and the probit model is based on the concept of generalized residuals proposed by Gourieroux et al. (1987). In order to obtain an additional information on the quality of our estimates we evaluate the sum of squared generalized residuals (SSGR) that gives a measure of the goodness of fit of the underlying latent model to the data.

According to the structural relationships (2.10)-(2.12) all coefficients from the probit estimation have the theoretically predicted sign except the coefficient of the wage rate which is negative in both equations. The impact of the concentration ratio on product and process innovations is positive but insignificant. Relative firm size, which reflects to some extent market power, has a significieant and relatively strong effect on product and process innovations. 
Table 1. Probit and cml-probit estimates ${ }^{a}$

\begin{tabular}{|c|c|c|c|c|}
\hline \multirow[t]{2}{*}{ RHS $^{b}$} & \multicolumn{2}{|c|}{ Product innovations } & \multicolumn{2}{|c|}{ Process innovations } \\
\hline & probit & cml-probit $^{\mathrm{c}}$ & probit & cml-probit ${ }^{c}$ \\
\hline const. & $\begin{array}{l}-3.029 \\
(-1.4)\end{array}$ & $\begin{array}{l}-26.959 \\
(-5.5)\end{array}$ & $\begin{array}{l}-3.579 \\
(-1.6)\end{array}$ & $\begin{array}{l}-18.014 \\
(-4.3)\end{array}$ \\
\hline$D D^{*}$ & $\begin{array}{l}0.272 \\
(4.1)\end{array}$ & $\begin{array}{l}0.423 \\
(4.7)\end{array}$ & $\begin{array}{l}0.177 \\
(2.7)\end{array}$ & $\begin{array}{l}0.267 \\
(3.5)\end{array}$ \\
\hline$D F^{*}$ & $\begin{array}{l}0.370 \\
(5.8)\end{array}$ & $\begin{array}{l}0.205 \\
(2.3)\end{array}$ & $\begin{array}{l}0.269 \\
(4.3)\end{array}$ & $\begin{array}{l}0.172 \\
(2.3)\end{array}$ \\
\hline$Q$ & $\begin{array}{l}0.311 \\
(8.6)\end{array}$ & $\begin{array}{l}0.765 \\
(7.7)\end{array}$ & $\begin{array}{l}0.159 \\
(4.5)\end{array}$ & $\begin{array}{l}0.418 \\
(5.0)\end{array}$ \\
\hline$S$ & $\begin{array}{l}0.176 \\
(8.8)\end{array}$ & $\begin{array}{l}0.896 \\
(6.8)\end{array}$ & $\begin{array}{l}0.172 \\
(8.7)\end{array}$ & $\begin{array}{l}0.592 \\
(5.3)\end{array}$ \\
\hline$K$ & $\begin{array}{l}0.022 \\
(0.5)\end{array}$ & $\begin{array}{l}-0.674 \\
(-5.2)\end{array}$ & $\begin{array}{l}0.041 \\
(1.0)\end{array}$ & $\begin{array}{l}-0.379 \\
(-3.5)\end{array}$ \\
\hline$w$ & $\begin{array}{l}-0.508 \\
(-2.2)\end{array}$ & $\begin{array}{l}0.741 \\
(1.9)\end{array}$ & $\begin{array}{l}-0.029 \\
(-0.1)\end{array}$ & $\begin{array}{l}0.757 \\
(2.3)\end{array}$ \\
\hline$\hat{v}_{1}(S)$ & & $\begin{array}{l}-0.733 \\
(-5.5)[-7.1]\end{array}$ & & $\begin{array}{l}-0.427 \\
(-3.8)[-4.2]\end{array}$ \\
\hline$\hat{v}_{2}(K)$ & & $\begin{array}{l}0.827 \\
(5.8)[7.1]\end{array}$ & & $\begin{array}{l}0.505 \\
(4.1)[4.5]\end{array}$ \\
\hline SSGR & 1345.57 & 1321.58 & 1393.17 & 1384.33 \\
\hline Pseudo $R^{2}$ & 0.093 & 0.115 & 0.061 & 0.070 \\
\hline $\begin{array}{l}\text { log-like- } \\
\text { lihood }\end{array}$ & -1440.32 & -1408.95 & -1502.52 & -1490.92 \\
\hline
\end{tabular}

${ }^{\text {a }} t$-Values in brackets;

${ }^{b}$ All continous explanatory variables in logs;

${ }^{c} t$-Values evaluated under the $H_{0}$ in squared brackets ( $t$-statistics of the exogeneity test).

If one is willing to interpret $D D^{*}$ and $D F^{*}$ as indicators for expected future profits in the sense of Schmookler (1966) and Scherer (1982), there is evidence that prospects on growing markets are one of the most important determinants of innovative activity. However, this reasoning is not in accordance with the causation of the theoretical model presented in Section 2 . There is a highly significant effect of total market size on innovations. Interestingly, the coefficient of $Q$ is relatively greater in comparison to the other variables within the product innovation equation than within the process innovation equation, indicating that market size is a stronger pace maker for product innovative activity than for process innovative activity.

Note that the coefficients in both equations are fairly similar in size despite the fact that the coefficients are identifiable only up to a scaling factor. Moreover, if the estimated coefficients are ranked by size, one finds the similar ranking for both equations. This might be regarded as a first indication that product and pro- 
Table 2. Diagnostic tests

\begin{tabular}{lcc}
\hline & Product innovations & Process innovations \\
\hline Skewness $(d f=1)$ & 0.531 & 0.247 \\
Kurtosis $(d f=1)$ & 0.008 & 0.739 \\
Normality $(d f=2)$ & 1.058 & 1.170 \\
${\text { Heteroskedasticity }(d f=6)^{\mathrm{a}}}_{\text {Neglected }(d f=26)^{\mathrm{b}}}$ & 17.303 & 11.747 \\
$\quad$ heterogeneity & 45.059 & 51.799 \\
Exogeneity $(d f=2)^{\mathrm{c}}$ & 62.616 & 23.271 \\
\hline
\end{tabular}

\footnotetext{
a Test for heteroskedasticity of known form using all explanatory variables (except the constant term) as potentially influencing the variance of the normal distributed error term.

${ }^{b}$ Since the regressor matrix of the auxiliary regression for the calculation of the test statistic is deficient in rank due to the two dummy variables the quadratic terms for these variables were dropped ending with 26 instead of $28 d f$ for the test.

${ }^{c}$ Score test for the joint test of $S$ and $K$ being weakly exogenous.
}

cess innovations result from the same optimizing process and that restrictions across equations exist.

Since the consistency of ML-estimates depends heavily on the accuracy of the distributional assumptions, a series of diagnostic tests is applied. Turning first to the underlying normality assumption of the probit model the Lagrange Multiplier Test proposed by Bera et al. (1984) is used to test for skewness, kurtosis and normality assuming under the alternative assumption that the distribution of the error term belongs to the Pearson family. For both equations skewness, kurtosis, and non-normality do not seem to be a specification problem. The surprisingly low test statistics indicate that normality cannot be rejected (see Table 2).

Another major source of misspecification in cross-section models is heteroskedasticity since it renders probit estimates inconsistent. We test for heteroskedasticity of known form by assuming a normal distributed error term of the form $u_{t} \sim N\left[0, \exp \left(2 z_{t}^{\prime} \delta\right)\right]$. Thus an LM-Test of the hypothesis $\delta=0$ will test the ordinary probit specification against the heteroskedastic alternative. Using different sets of explanatory variables for the variance there is no indication for the absence of homoskedasticity [Davidson and MacKinnon (1984)]. Many unobservable variables of the theoretical model like the unit costs of innovations and the capital stock are only captured by the constant and the error term. As a general test of misspecification we apply the Information Matrix test which is particularly useful in cross section approaches in order to test for neglected heterogeneity across individual firms [Chesher (1984)]. For a high significance level of 0.001 the hypothesis of neglected parameter heterogeneity can be rejected. 
Having tested that the distributional assumptions do not cause serious specification problems, we finally have to deal with the problem of simultaneity. The Smith-Blundell test was carried out for both equations. First, it was tested whether $S$ or $K$ can be treated as weakly exogenous. The coefficients on the residuals are highly significant, indicating that none of the relevant variables is weakly exogenous. In a second step the joint hypothesis was tested. Again there is strong evidence that both, the product and the process innovation equation, suffer from a simultaneous equation bias. The comparatively high test statistics reveal that endogeneity is the major source of misspecification in our model. The results support previous finding by Levin and Reiss (1984) based on US data at the industry level.

Accounting for endogeneity by using conditional maximum likelihood probit the coefficient on the wage rate has the predicted positive sign in both equations and is significant. However, contrary to the specification (2.10) and (2.11) the sign of the concentration ratio turns out to be negative. The sign pattern of the other coefficients remains the same as in the probit estimates. While the impact of the prospects with respect to foreign demand in the probit estimates was stronger than the one for the domestic market, the cml-probit estimates reveal the opposite result. The importance of relative firm size and market size in comparison to the other determinants becomes more obvious. Finally, accounting for endogeneity improves the fit for the product innovation equation more than for the process innovation equation, which is reflected by the higher $t$-values for the coefficients of the residuals as well as by the stronger improvement in the Pseudo $R^{2}$ values. The two goodness of fit measures reveal similar behavior. The product innovation equation fits the data somewhat better than the process innovation equation does. Conditional maximum likelihood estimation does not change the similarities of the coefficients between the two equations.

While the probit estimations allow for different variances of the error terms, they ignore a possible correlation between the error terms. If we assume that the error terms are correlated but the variances of the error terms are the same for the product and the process innovation equation, it is possible to estimate Eqs. (2.10) and (2.11) within a bivariate probit model. Restricting the variances to equality implies that restrictions on the coefficients across equations can be introduced according to the theoretical model. However, the scaling problem remains unsolved for the given specification unless one is willing to assume that the error terms are drawn from a bivariate standard normal distribution.

In fact, with a sightly different specification, that is in our case not feasible due to the lack of data, it is possible to identify the variance. This can be done by assuming $\gamma=1$ and introducing a cost function for product innovations as $G(I)=\omega_{0} I^{\omega}, \omega>1$. If data on relative firm size measured in terms of output rather than employment were available, $m_{i}$ could be introduced according to Eq. (2.6) without using an approximation. The inverse of the coefficient of $\ln \left(1-m_{i}\right)$ would be the standard deviation of the error term.

The model was estimated in two different versions by bivariate probit. In a first step it was assumed $\gamma=1$. This simplifies the estimation since the quasi con- 
Table 3. Bivariate probit estimates ${ }^{\mathrm{a}}$

\begin{tabular}{lcc}
\hline & $\gamma=1$ & $\gamma \neq 1$ \\
\hline$c_{I}$ & -4.449 & -4.444 \\
& $(-3.0)$ & $(-2.9)$ \\
$a_{1}$ & 0.198 & 0.176 \\
& $(3.2)$ & $(3.0)$ \\
$a_{2}$ & 0.306 & 0.272 \\
& $(5.2)$ & $(4.5)$ \\
$a_{3}$ & 0.072 & 0.066 \\
& $(4.2)$ & $(3.9)$ \\
$a_{4}$ & -0.033 & -0.029 \\
& $(-0.9)$ & $(-0.8)$ \\
$\varepsilon$ & 8.401 & 9.560 \\
& $(4.6)$ & $(4.1)$ \\
$\alpha$ & 0.103 & 0.074 \\
& $(0.6)$ & $(0.5)$ \\
$c_{T}$ & -4.890 & -4.875 \\
& $(-3.3)$ & $(-3.2)$ \\
$\gamma$ & & 0.8501 \\
& & $(9.2)$ \\
$\varrho$ & 0.537 & 0.536 \\
& $(19.7)$ & $(19.7)$ \\
$L R(d f=1)^{b}$ & & 17.98 \\
log-likelihood & -2894.22 & -2885.23 \\
Pseudo $R^{2}$ & 0.173 & 0.179 \\
\hline & &
\end{tabular}

${ }^{\text {a }} t=$ Values in brackets;

${ }^{\mathrm{b}}$ Likelihood ratio test for $\gamma=1$.

ditional factor demands are both linear in parameters and the equation for process innovations is independent of $m_{i}$. Unfortunately, the profit maximization problem is not well defined for this case, although the results of the comparative statics do not change. The bivariate probit estimation results are given in Table 3.

All coefficients have the theoretically predicted sign except the coefficient of the concentration ratio, $\boldsymbol{a}_{4}$, which is negative but insignificant. Since this result confirms the findings from the cml-probit estimates, where the coefficient of $K$ was significantly negative, one may conclude that the Cournot assumption is not valid. When the Cournot assumption is relaxed, the effect of $K$ on $m_{i}$ can no longer be signed. The sign of the wage rate is positive but insignificant. The relevance of expectations about the growth of markets finds another confirmation. The highly significant estimated correlation coefficient of more than 0.5 makes clear that single-equation approaches suffer from inefficiency.

The effect of the relative firm size is not as strong as the effect of $D D^{*}$ and $D F^{*}$ on innovations. This result is in accordance with the probit but not with the cml-probit estimates. Note that in the nonlinear version $(\gamma \neq 1) \gamma$ is exactly iden- 
tified while the remaining parameters are only identifiable up to a scaling factor. However, assuming $0<\alpha<1$ one can evaluate bounds for the other parameters. This little exercise gives quite interesting results, e.g. the lower bound for $\varepsilon$ is 0.71 indicating that the response of total market demand to a price change might be inelastic. The upper bounds for the elasticities of product and process innovations w.r.t. relative firm size are 1.05 and 0.16 . Hence an overproportional relationship between innovation and firm size can be ruled out for process innovations but not for product innovations.

\section{Concluding Remarks}

In this study explicit attention has been paid to the role of market structure variables that, in the neo-Schumpeterian literature, are regarded to be major sources of innovations. Structural equations were derived from a neoclassical competitive fringe model relating product and process innovations to factor prices and market structure variables. Although these equations are observationally equivalent to a neo-Schumpeterian causation, they do not reflect a causal relationship. In fact, this simple model enables us to show that empirical findings supporting various Schumpeterian hypotheses might be misleading. In this model market concentration, market size and relative firm size are not predetermined but result from the same optimizing process.

The resulting potential endogeneity was accounted for by testing for exogeneity and applying the conditional maximum likelihood probit estimator. The estimation results show that care should be taken in using market structure variables in order to explain innovations since they are likely to be endogeneous even in cross sections at the firm level. Our empirical findings support a feature that is common to the theoretical literature on Schumpeterian and monopolistic competition, strategic entry deterrence, and contestability: the endogeneity of market structure.

By choosing appropriate assumptions about the error term structure, it was possible to estimate a structural model with qualitative dependent variables. Results obtained by nonlinear bivariate probit analysis differed from the probit estimates as well. The correlation between the error terms of the regression equations for product and process innovations turned out to be highly significant. The results of cml-probit and bivariate point in the same direction and generally confirm the results predicted by theory. The only exception is the concentration ratio that turned out to have a negative impact on the price-cost margin, indicating that the Cournot assumption is not consistent with the data. Simultaneity, both in the sense of endogenous variables and in the sense of cross-equation correlations does matter.

Finally, a number of shortcomings have to be mentioned. The derived quasiconditional factor demand functions do not reflect equilibrium behavior but rath- 
er solely optimal behavior in terms of first-order conditions. The theoretical model is set up as an input demand model and assumes that innovative inputs are transformed on a one-to-one basis to innovative outputs. The model can be extended by introducing production functions relating innovative input variables to innovative output variables as they are used in this econometric model. The assumptions about isoelastic responses should be relaxed in future studies. Economic model and data construction do not coincide. The definition of the $n$ firm concentration ratio should vary for the different industries, depending on the number of monopolistic competitors. For a given firm size measure defined in output terms, a three equation approach including a demand function for labor would be feasible. A lot of important variables are only taken care of in the constant terms and the residuals.

Future research should be directed towards a relaxation of various restrictive assumptions (e.g. the Cournot assumption, the Cobb-Douglas form). Moreover, in the approach presented here, product and process innovations are rather different decision parameters of the firm's profit maximization problem. Since product innovations implicitly cause process innovations and vice versa, one should account for this by a more appropriate choice of the production function and the cost scheme.

\section{Appendix A.I: Descriptive Statistics of the Data}

\begin{tabular}{|c|c|c|c|c|c|}
\hline & & Mean & Std. Dev. & Minimum & Maximum \\
\hline Realized product innovation & $I$ & 0.568 & 0.495 & 0 & 1 \\
\hline Realized process innovation & $T$ & 0.485 & 0.500 & 0 & 1 \\
\hline Number of employees & $N$ & 493.830 & 488.888 & 3 & 57498 \\
\hline $\begin{array}{l}\text { Average labour costs per } \\
\text { employee (in DM) }\end{array}$ & $W$ & 50985.63 & 50986.01 & 33712 & 89841 \\
\hline $\begin{array}{l}\text { Three-firm concentration ratio } \\
\text { (by percentage) }\end{array}$ & $K$ & 14.60 & 12.55 & 3.9 & 75.2 \\
\hline $\begin{array}{l}\text { Expected long-run change of } \\
\text { external demand }\end{array}$ & $D F^{*}$ & 0.545 & 0.498 & 0 & 1 \\
\hline $\begin{array}{l}\text { Expected long-run change of } \\
\text { internal demand }\end{array}$ & $D D^{*}$ & 0.363 & 0.481 & 0 & 1 \\
\hline Market size (in billions DM) & $Q$ & 68783.94 & 69785.22 & 1531 & 169719 \\
\hline Relative firm size & $S$ & 0.002 & 0.008 & 0 & 0.159 \\
\hline Number of firms in the industry & & 2615.80 & 2608.78 & 68 & 5258 \\
\hline $\begin{array}{l}\text { Percentage share of sales } \\
\text { going to exports }\end{array}$ & & 29.07 & 25.83 & 3.8 & 58.5 \\
\hline $\begin{array}{l}\text { Consumer goods dummy } \\
\text { (=1, if firm is operating in the } \\
\text { consumer goods industry) }\end{array}$ & & 0.389 & 0.488 & 0 & 1 \\
\hline $\begin{array}{l}\text { Investment goods dummy } \\
(=1 \text {, if firm is operating in the } \\
\text { investment goods industry) }\end{array}$ & & 0.500 & 0.500 & 0 & 1 \\
\hline
\end{tabular}




\section{References}

Aldrich JH, Nelson F (1984) Linear probability, logit, and probit models. Quantitative Applications in the Social Sciences, Beverly Hills

Amemiya $T$ (1978) The estimation of a simultaneous equation generalized probit model. Econometrica 46:1193-1205

Amemiya T (1979) The estimation of a simultaneous equation tobit model. International Economic Review 20:169-181

Bera AK, Jarque CM, Lee LF (1984) Testing the normality assumption in limited dependent variable models. International Economic Review 25:563-578

Chesher A (1984) Testing for neglected heterogeneity. Econometrica 52:865-872

Coombs R, Saviotti P, Walsh V (1987) Economics and technical change. Houndmills and London

Dasgupta P, Stiglitz JE (1980a) Industrial structure and the nature of innovative activity. The Economic Journal 90:266-293

Dasgupta P, Stiglitz JE (1980b) Uncertainty, industrial structure, and the speed of R\&D. Bell Journal of Economics 11:1-28

Davidson R, MacKinnon JG (1984) Convenient specification tests for logit and probit models. Journal of Econometrics 25:241-262

Engle RF, Hendry DF, Richard JF (1983) Exogeneity. Econometrica 51:277-304

Entorf H, Pohlmeier W (1990) Innovation, employment and export activity. Evidence from firm level data. In: Forens JP, Ivaldi M, Laffont JJ, Laisney F (eds) Microeconometrics: surveys and applications. Oxford, 394-415

Futia C (1980) Schumpeterian competition, Quarterly Journal of Economics 94:675-695

Galbraith JK (1952) American capitalism: The concept of coutervailing power. Cambridge

Griliches Z (ed) (1984) R\&D, patents, and productivity. Chicago

Gourieroux C, Monfort A, Renault E, Trognon A (1987) Generalized residuals. Journal of Econometrics 34:5-32

Heckman JJ (1978) Dummy endogenous variables in a simultaneous equation system. Econometrica 46:931-959

Kamien MI, Schwartz NL (1969) Induced factor augmenting technical progress form a microeconomic viewpoint. Econometrica 37:668-684

Kamien MI, Schwartz NL (1982) Market structure and innovation. Cambridge

Lee T, Wilde LL (1980) Market structure and innovation: A reformulation. Quarterly Journal of Economics 94:429-436

Levin RC, Reiss PC (1984) Tests of a Schumpeterian model of R\&D and market structure. In: Griliches $Z$ (ed) $R \& D$, patents, and productivity. Chicago 175-204

Link AN (1978) Rates of induced technology from investment in research an development. Southern Economic Journal 45:370-379

Link AN (1980) Firm size and efficient entrepreneurial activity: A reformulation of the Schumpeter Hypothesis. Journal of Political Economy 88:771-782

Nelson F, Olsen L (1978) Specification and estimation of a simultaneous equation model with limited dependent variables. International Economic Review 19:695-705

Neumann M, Böbel I, Haid A (1985) Domestic concentration, foreign trade, and economic performance. International Journal of Industrial Organisation 3:1-19

Newey WK (1987) Efficient estimation of limited dependent variable models with endogenous explanatory variables. Journal of Econometrics 36:231-250

Pohlmeier W (1989) Simultane Probit- und Tobitmodelle, Theorie und Anwendungen auf Fragen der Innovationsökonomik. Heidelberg

Scherer FM (1980) Industrial market structure and economic performance. 2nd ed., Chicago

Scherer FM (1982) Demand pull, and technological invention: Schmookler revisited. Journal of Industrial Economics 30:225-237

Scherer FM (1984) Innovation and economic growth. Cambridge 
Schmookler J (1966) Invention and economic growth. Cambridge Schumpeter JA (1934) The theory of economic development. Cambridge Schumpeter JA (1942) Capitalism, socialism, and democracy. New York

Smith RJ, Blundell RW (1986) An exogeneity test for a simultaneous equation tobit moủel with an application to labor supply. Econometrica 54:679-685

First version received: November 1989

Final version received: June 1990 